\title{
CLIMATOLOGIA REgIONAL DA PRECIPITAÇÃO NO ESTADO DO PARÁ
}

\author{
LOPES, Marcio Nirlando Gomes - marcio.lopes@sipam.gov.br \\ Centro Gestor e Operacional do Sistema de Proteção da Amazônia-CENSIPAM \\ Programa de Pós-Graduação em Ciências Ambientais-PPGCA/Univ. Federal do Pará-UFPA \\ DE SOUZA, Everaldo Barreiros - everaldo@ufpa.br \\ Programa de Pós-Graduação em Ciências Ambientais-PPGCA/Univ. Federal do Pará-UFPA \\ Instituto Tecnológico Vale-ITV
}
FERREIRA, Douglas Batista da Silva - ferreira.douglas@gmail.com Instituto Tecnológico Vale-ITV

\begin{abstract}
RESUMO
Dados pluviométricos de 150 estações meteorológicas de superfície distribuídas pelo estado do Pará e circunvizinhança foram integrados para compor uma nova base denominada RPCH. A base RPCH compreende uma série histórica de trinta anos (19782007). Este estudo gerou uma climatologia recente que permitiu identificar melhor a variabilidade climática regional, sobretudo influenciada pelos aspectos da fisiografia local e a contribuição de sistemas de grande escala. Uma análise comparativa entre dados do GPCP, CMAP e CPC com a nova climatologia RPCH foi realizada, destacando o ganho obtido com a integração dos dados observacionais. O Nordeste paraense mostrou-se o setor mais chuvoso do Estado ao longo do ano. Mas, diferentemente do que se conhecia, um núcleo de precipitação significativa foi observado no Noroeste paraense. A ilha do Marajó apresentou certa variabilidade espacial na estação chuvosa, com índices mais expressivos na porção Leste, marcadamente influenciada por circulações de brisa e pela Zona de Convergência Intertropical, com volume de chuva reduzindo-se em direção ao Oeste. A chuva climatológica RPCH no Sudoeste paraense durante o verão austral mostrou-se superior às bases GPCP, CMAP e CPC. Esta nova climatologia tem importância em vários segmentos da economia do Estado, como indústria, comércio, turismo, agricultura, produção mineral, geração de energia.
\end{abstract}

Palavras-chave: Precipitação. Climatologia. Pará. REGIONAL CLIMATOLOGY FOR PRECIPITATION TO PARÁ STATE.

ABSTRACT. Precipitation data from 150 surface meteorological stations distributed throughout the state of Pará and surrounding region were integrated to form a new base, called RPCH. The RPCH base comprises a historical series about thirty years (19782007). This study generated a recent climatology that allowed better identify the regional climate variability, mainly influenced by aspects of local physiography and the contribution of large-scale systems. A comparative analysis from GPCP, CMAP and CPC data with the new RPCH climatology was also held, highlighting the gains from the integration of observational data. The Northeastern of Pará showed the rainiest sector of the State throughout the year. But, unlike what was known until then, a significant core of precipitation was observed in Northwestern Para. The Marajó Island presented some spatial variability in the rainy season, with more significant rates to the East sector, markedly influenced by breeze circulations and by the Intertropical Convergence Zone, with rainfall volume reducing towards the west. The RPCH climatological rainfall in southwestern Pará during the austral summer proved superior to the GPCP, CMAP and CPC bases. This new climatology is very important for a range of segments of the state's economy, such as industry, trade, tourism, agriculture, mineral production and power generation.

Keywords: Rainfall. Climatology. Pará. 


\section{INTRODUÇÃO}

A relevância de informações e produtos de clima em ambas as escalas, regional e global, além do interesse crescente por dados meteorológicos, sobretudo nos dias atuais, tem criado programas internacionais, alguns de cooperação entre várias nações, de modo a obter informações generalizadas das variáveis meteorológicas ao redor do globo. Projetos e produtos operacionais como o Global Precipitation Climatology Project (GPCP) e o Climate Prediction Center Merged Analysis of Precipitation (CMAP) têm tratado de compilação de bases de dados mundial proveniente de estações meteorológicas de superfície e derivados de satélites orbitais para compor uma climatologia global da precipitação.

Atualmente o instituto oficial responsável pela meteorologia no Brasil dispõe de uma climatologia para a Amazônia com baixa resolução espacial (Normais Climatológicas 1961-1990), visto que até o início dos anos 1980, o mesmo dispunha de pouquíssimas estações meteorológicas na região, além de uma distribuição espacial que favorecia grandes áreas sem cobertura e, portanto, com pouca ou nenhuma representatividade. Pontos de difícil acesso e logística complicadíssima, os quais não são raros de encontrar na região, mesmo nos dias atuais, muitas vezes são providos de informações de redes paralelas que não constam na base de dados oficiais, necessitando assim, integrar um banco único para aperfeiçoar, atualizar e melhor informar a sociedade sobre as reais condições climáticas da região.

Dada a relevância que o clima ocupa no cenário político-técnico-científico, diversos estudos já realizados permitiram que a comunidade científica compreendesse que a característica intrínseca do clima da Amazônia é a presença de um amplo espectro de variações no tempo e espaço da atividade convectiva tropical e da precipitação (SOUZA et al., 2009). Na verdade, esta última variável climática pode ser considerada a mais importante na região. Sabe-se, ainda, que a maior parte da precipitação sobre o estado paraense ocorre entre as estações de verão e outono austral (FIGUEROA; NOBRE, 1990; MARENGO et al., 2001; SOUZA; AMBRIZZI, 2003), em associação, principalmente, aos padrões de circulação atmosférica quase-estacionários de grande escala ligados à Zona de Convergência do Atlântico Sul (ZCAS) e Zona de Convergência Intertropical (ZCIT).

A Zona de Convergência do Atlântico Sul é um fenômeno meteorológico de escala intrassazonal que influencia a distribuição de precipitação, sendo em muitos casos, responsável por variabilidades no clima regional (KODAMA, 1992; QUADRO, 1994; NOGUES-PAEGLE; MO, 1997; LIEBMANN et al., 1999). Assim sendo, o Pará também está sujeito aos efeitos da ZCAS, que tem sua maior frequência nos meses de verão, coincidindo com a estação chuvosa e afetando os índices pluviométricos, principalmente na porção Sul do Estado. É comum nestes episódios, haver um acoplamento da ZCAS com a ZCIT, em associação com sistemas como a Alta da Bolívia e vórtices ciclônicos em altos níveis, o que pode provocar chuvas generalizadas sobre grande parte do Estado (GAN; KOUSKY, 1986; SOUZA; AMBRIZZI, 2003).

A ZCIT, por sua vez, exerce um papel preponderante na modulação do regime pluviométrico na região equatorial, podendo ser considerada o sistema meteorológico de grande escala de maior importância no Pará, visto que concorre para o estabelecimento do período chuvoso do Estado no decorrer de sua marcha em direção ao hemisfério Sul, durante o verão e outono austral. Através de sua climatologia, Waliser e Gautier (1993) mostraram a importância 
deste sistema na definição e análise do clima terrestre em escala global e local. Assim, a sua variabilidade sazonal e interanual em decorrência de interações com as condições oceânicas, principalmente no Atlântico Tropical, têm implicação direta na duração e intensidade da estação chuvosa paraense. Por outro lado, a ocorrência de sistemas de mesoescala, como as linhas de instabilidade, pode ser responsável por até $45 \%$ da precipitação na parte Leste do Pará (COHEN; DIAS; NOBRE, 1989).

Pesquisas têm mostrado que as condições oceânicas, sobretudo a temperatura da superfície do mar (TSM), apresentam influência marcante sobre o clima global e regional, cujas evidências observacionais e simulações numéricas podem ratificar esta afirmativa. Um fenômeno climático de interação oceanoatmosfera bastante investigado é o El Niño-Oscilação Sul (ENOS). Esta variabilidade climática, com periodicidade variando de 3 a 7 anos, pode ser detectada por meio de anomalias persistentes de TSM, com duração igual ou superior a cinco meses consecutivos (TRENBERTH, 1997), ou seja, aquecimento/resfriamento das águas superficiais no Pacífico Equatorial. Tanto a fase quente (El Niño), quanto a fase fria (La Niña) do ENOS, alteram a circulação em escala global, afetando o clima em diversos pontos do planeta (ROPELEWSKI; HALPERT, 1987; KILADIS; DIAZ, 1989).

A influência dos episódios de ENOS sobre a variabilidade climática interanual da América do Sul, sobretudo na Amazônia e Nordeste Brasileiro (NEB) tem sido objeto de estudo por muitos pesquisadores, principalmente no tocante às áreas afetadas por excessos e deficiências de precipitação (KOUSKY; KAYANO; CAVALCANTI, 1984; KAYANO; RAO; MOURA, 1988; SOUZA et al., 2000; SOUZA; KAYANO; AMBRIZZI, 2005). Em particular, no estado do Pará, o El Niño pode representar uma estação chuvosa com índice pluviométrico abaixo do normal, visto que a circulação zonal de Walker é perturbada, resultando, de certo modo, subsidência sobre grande parte do Estado (RICKEY; NOBRE; DESER, 1989; SOUZA; KAYANO; AMBRIZZI, 2005; RAMOS DA SILVA; WERTH; AVISSAR, 2008). Por outro lado, o La Niña responde pelo padrão inverso de circulação observado na fase quente (SOUZA; KAYANO; AMBRIZZI, 2005).

A Amazônia é uma região grandemente afetada pelas circulações atmosféricas e oceânicas do Atlântico Tropical (MOLION, 1987; MOLION, 1993; NOBRE; SHUKLA, 1996; SOUZA; NOBRE, 1998). Estudos realizados por Uvo (1989) e Souza et al. (2000) mostraram que a variabilidade interanual da circulação de grande escala sobre o oceano Atlântico Tropical, inerente às alterações na pluviometria local, está intimamente relacionada às anomalias de TSM, que podem dar origem a um gradiente inter-hemisférico entre o Atlântico Tropical Norte e Sul. Este gradiente surge em situações em que a bacia do Atlântico Norte está aquecida (resfriada) e a bacia do Atlântico Sul está resfriada (aquecida), e afeta de forma direta o posicionamento da ZCIT, contribuindo para a modulação das anomalias de precipitação sobre o Pará.

Assim, de certo que o estudo da variabilidade da precipitação decorrente de fenômenos de interação oceano-atmosfera constitui objeto de extrema relevância diante da nova base construída, este não será abordado neste momento, mas sim num próximo estudo, em virtude da riqueza de resultados encontrados, o que justifica a continuidade desta pesquisa.

Números oficiais recentes apontam o Pará como um dos estados que mais se destacam na região Amazônica, não apenas por suas riquezas naturais, mas, sobretudo, pela economia em progressivo crescimento. De todos os estados da região Norte do país, o Pará tem o maior número de municípios, 144, e a maior 
população, superior a sete milhões de habitantes (Censo IBGE, 2007), ocupando assim, posição de destaque na região. Dada a sua posição geográfica, a maior parte do estado do Pará experimenta pequenas variações ao longo do ano quanto à maioria das variáveis climáticas como temperatura do ar, insolação, umidade, direção e velocidade dos ventos. Entretanto, o índice pluviométrico apresenta marcadamente duas estações, sendo uma bastante chuvosa, regionalmente conhecida como inverno Amazônico, e outra considerada seca, a qual pode ser chamada de verão Amazônico.

Adicionalmente, o Pará é o estado da Amazônia que possui a maior rede de drenagem, contemplando assim grandes bacias hidrográficas, de modo que os rios adquirem relevância única na vida da população. O regime hidrológico, entretanto, pode ser severamente afetado em decorrência da falta ou excesso de chuvas. Diante de tal circunstância, as atividades econômicas ligadas aos setores da agricultura, turismo, transporte, energia, indústria, entre outros, são diretamente dependentes e amplamente influenciados pela variabilidade pluviométrica regional. Visto que boa parte de seus habitantes exerce atividades que estão intimamente ligadas às condições climáticas e ambientais, conhecer detalhadamente o clima e sua variabilidade em diferentes escalas (anual, sazonal e intrassazonal) constitui um instrumento extremamente eficaz quando resulta em informações estratégicas que podem ser utilizadas para prover o desenvolvimento, uma vez que permite o planejamento das ações de governo, assim como de instituições privadas. Sob este escopo, este trabalho se propõe analisar comparativamente diferentes bases pluviométricas e integrar dados observacionais de estações meteorológicas de superfície, para constituir uma nova climatologia para a precipitação no estado do Pará utilizando apenas dados observacionais e permitindo maior detalhamento das características da chuva, incluindo a influência sofrida pela fisiografia peculiar do Estado do Pará.

\section{MATERIAIS E MÉTODOS}

\section{PRECIPITAÇÃO}

\section{Precipitação regional}

Este trabalho abordou os totais mensais de precipitação para um conjunto de 150 estações meteorológicas de superfície (EMS) distribuídas sobre a Amazônia Oriental (Figura 1), com ênfase nas estações instaladas no estado do Pará e sua vizinhança. Foram analisados trinta anos de registros, compreendendo o período de 1978 a 2007. Os registros meteorológicos considerados envolveram dados da Empresa Brasileira de Pesquisa Agropecuária (EMBRAPA), da Secretaria Estadual de Meio Ambiente (SEMA-PA) que trabalha em parceria com o Instituto Nacional de Pesquisas Espaciais/Centro de Previsão do Tempo e Estudos Climáticos (INPE/CPTEC), do Instituto Nacional de Meteorologia (INMET) e da Agência Nacional de Águas (ANA), sendo que as EMS da ANA são operadas na região pela Companhia de Pesquisa de Recursos Minerais (CPRM) e Centrais Elétricas do Norte do Brasil (Eletronorte). Esta base de dados, devidamente integrada, passou a constituir o novo banco climatológico do projeto Rede Estadual de Previsão Climática e Hidrometeorológica do Pará (RPCH). 


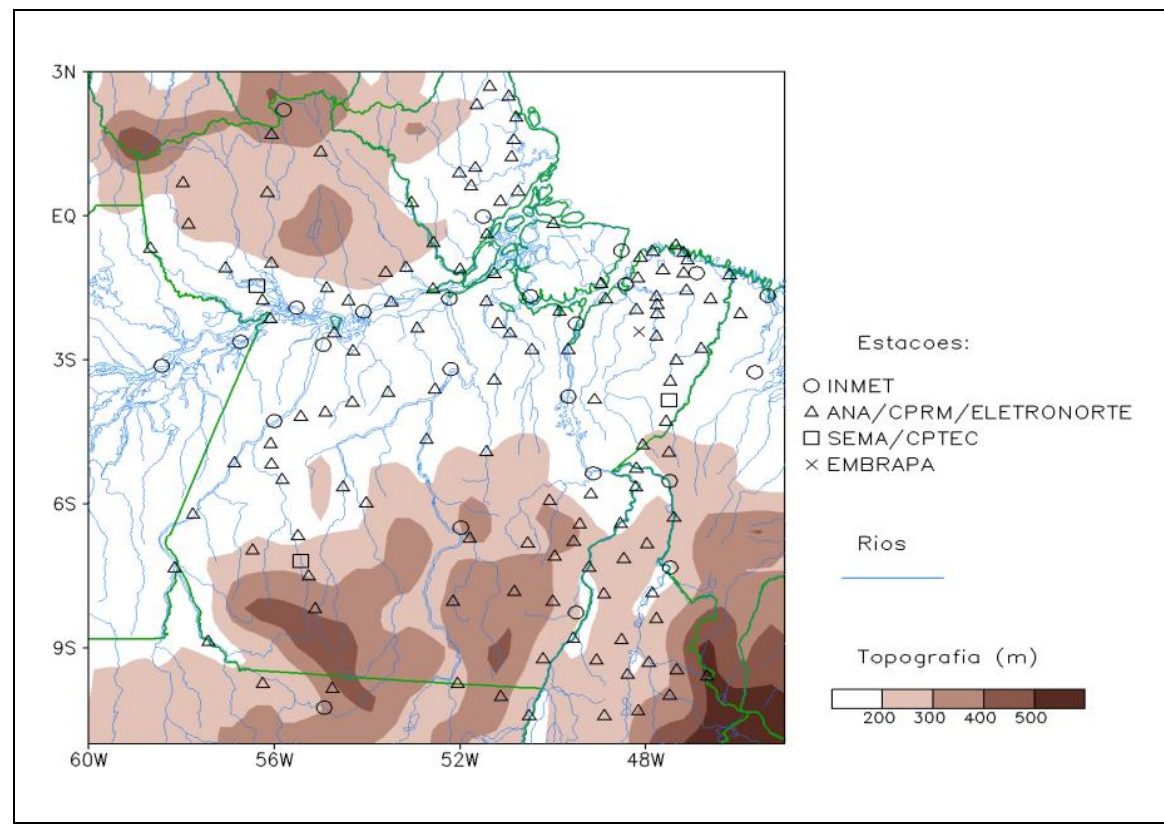

Figura 1 - Localização das estações pluviométricas no estado do Pará e circunvizinhança usadas para gerar a climatologia da precipitação da Rede de Previsão Climática e Hidrometeorológica (RPCH).

Este novo conjunto de dados foi submetido a um rigoroso controle de qualidade, de acordo com os critérios apresentados em Higgins et al. (2000), aplicando-se técnicas que permitiram excluir as informações duvidosas, errôneas e omissas, levando-se em consideração o desvio padrão superior a três vezes o valor médio. Assim, selecionou-se apenas as EMS cujos registros continham índice inferior a $5 \%$ de dados faltantes. As falhas, por sua vez, foram interpoladas, utilizando-se para tal os dados de estações próximas por meio de regressão linear múltipla (PARTHASARATHY \& MOOLEY; 1978).

A fim de obter um conjunto de dados de precipitação regional em pontos de grade no domínio do Pará, foi empregada a interpolação espacial (utilizando o método do inverso das distâncias ao quadrado) dos dados coletados de estações meteorológicas/hidrometeorológicas para uma grade regular com resolução de $0.27^{\circ}$ latitude $\times 0.27^{\circ}$ longitude. Este novo conjunto de dados foi denominado de precipitação $\mathrm{RPCH}$, sendo comparado a posteriori com outras bases de dados de precipitação, a saber: o GPCP (ADLER et al., 2003), o CMAP (XIE; ARKIN, 1997; 1998) e o CPC-NCEP (SILVA et al., 2007) que possuem resoluções espaciais mais baixas.

\section{Precipitação de outras bases}

Outras fontes de dados de precipitação, descritas a seguir, foram utilizadas como análise comparativa e qualitativa sobre consistência da integração dos dados pluviométricos da RPCH e a geração da nova climatologia regional com maior detalhamento.

O Global Precipitation Climatology Project (GPCP) foi estabelecido pelo World Climate Research Program (WCRP) com o objetivo de prover informações cruciais sobre a distribuição temporal e espacial da precipitação sobre o globo. Disponíveis desde 1979, estes dados são públicos, encontram-se, atualmente, 
disponíveis na internet e são gerados incorporando dados de estimativas por satélites, particularmente, nos canais de microondas e infravermelho, combinados com dados de pluviômetros. Sobre o continente, os vieses de análises de multi-satélites são ajustados por análises de pluviômetros, enquanto que o ajuste sobre o oceano não é realizado. A disponibilização dos dados é diária, existindo também uma climatologia mensal, com informações distribuídas em uma grade de $2.5^{\circ}$ latitude $\times 2.5^{\circ}$ longitude (HUFFMAN et al., 1997; ADLER et al., 2003).

O Climate Prediction Center Merged Analysis of Precipitation (CMAP) surgiu em 1997, com o objetivo de gerar uma climatologia global de precipitação baseada tanto em dados observacionais de pluviômetros, quanto em estimativas por satélite, disponibilizados abertamente ao público. A metodologia empregada assemelha-se bastante a do GPCP, porém não fornece dados diários, apenas mensais. A resolução também refere-se a uma grade de $2.5^{\circ}$ latitude $\times 2.5^{\circ}$ longitude (XIE; ARKIN, 1997; 1998).

Os dados originários do Climate Prediction Center (CPC) são diários, provenientes apenas de pluviômetros, para uma grade sobre o Brasil com resolução de $1.0^{\circ}$ latitude $\times 1.0^{\circ}$ longitude, utilizando o esquema de Cressman modificado para a interpolação dos dados (SILVA et al., 2007). Esta base também está disponibilizada publicamente, porém foi descontinuada em 2010.

\section{DADOS ATMOSFÉRICOS}

Os dados mensais de radiação de onda longa (ROL) derivados dos satélites meteorológicos de órbita polar (LIEBMANN; SMITH, 1996), estão disponíveis a partir de 1974, compreendendo mais de 30 anos de dados, e foram utilizados neste trabalho para gerar a caracterização da atividade convectiva tropical. Os dados de ROL encontram-se dispostos numa grade regular com resolução de $2.5^{\circ}$ latitude $\times 2.5^{\circ}$ longitude.

Utilizou-se também os dados mensais das componentes zonal e meridional do vento, velocidade vertical do NCEP/NCAR (KALNAY et al., 1996) gerados através de um consistente sistema de assimilação de dados empregado no modelo de circulação geral (MCG) do NCEP com resolução T62L28 (aproximadamente 210 $\mathrm{km}$ em latitude/longitude e 28 níveis verticais).

\section{MÉTODOS DE ANÁLISE OBSERVACIONAL}

\section{Percentis}

Os dados de precipitação sofreram um tratamento estatístico simples, porém apropriado, visando distribuir em classes as variáveis em estudo, de modo a definir limites para os índices pluviométricos em uma categoria considerada normal. A técnica dos quantis aqui empregada é uma metodologia que consiste estritamente na distribuição em ordenamento crescente de uma série amostral contínua, neste caso, o conjunto de dados mensais de chuva para um período de trinta anos, para o qual atribui-se uma probabilidade $p$ univocamente para cada valor amostral (XAVIER, 1999; XAVIER et al., 2002). Assim, a série temporal pode ser distribuída da seguinte forma: $\left\{x_{1}, x_{2}, x_{3}, \ldots, x_{n}\right\}$, onde $x_{1}$ representa o menor valor e $x_{n}$ o maior valor da série. 0 índice $n$, portanto, constitui o tamanho da amostra. Após a determinação das ordens quantílicas, é realizada a classificação em grupos, cujas ordens quantílicas $q_{0,35}$ e $q_{0,65}$ foram reservadas para estabelecer as seguintes classes com relação aos valores mensais observados $\left(x_{i}\right)$ de precipitação: 


\begin{tabular}{lll}
\hline \multicolumn{3}{c}{ Classes de Precipitação } \\
\hline ABAIXO DO NORMAL (SECO) & quando & $x_{i} \leq q_{0,35}$ \\
\hline NORMAL & quando & $q_{0,35}<x_{i}<q_{0,65}$ \\
\hline ACIMA DO NORMAL (CHUVOSO) & quando & $x_{i} \geq q_{0,65}$ \\
\hline
\end{tabular}

Tabela 1. Intervalos de classe para categorização da precipitação.

As classes acima permitem, portanto, selecionar de forma objetiva e rápida os eventos climáticos anômalos e de interesse para estudo em um determinado mês $i$, tais como episódios de extremos secos e chuvosos, bem como o padrão normal.

\section{RESULTADOS E DISCUSSÃO}

\section{ANÁLISE OBSERVACIONAL DA PRECIPITAÇÃO CLIMATOLÓGICA Comportamento anual}

A distribuição espacial e temporal da precipitação na Amazônia já foi objeto de diversos estudos pretéritos (FIGUEROA; NOBRE, 1990; MARENGO, 1995; PAIVA; CLARK, 1995), denotando o caráter relevante deste elemento climático. $\mathrm{Na}$ região tropical, em face à pequena variação anual na radiação solar média incidente à superfície atmosférica (SALATI; MARQUES, 1984), as chuvas podem, eventualmente, influenciar o comportamento de outras variáveis, como temperatura, umidade relativa do ar, ventos, etc. (FISCH; MARENGO; NOBRE, 1998). Para avançar no conhecimento sobre a climatologia da precipitação no estado do Pará foi necessário obter um conjunto de dados com uma série temporal razoável, consistente e com o mínimo possível de falhas, além de boa distribuição sobre a região.

Ao longo dos anos, foram criadas na Amazônia, principalmente pelos órgãos de governo, algumas redes de estações meteorológicas e hidrológicas, dotadas de pessoal, ou completamente automatizadas, para atender a objetivos específicos de cada instituição. Entretanto, nenhuma destas redes isoladamente pode oferecer uma cobertura apropriada para o Pará, com a densidade de dados suficiente para gerar informações mais precisas e representativas da região de modo a permitir melhor compreensão dos fenômenos atmosféricos precipitantes.

Visto que o Pará apresenta uma dimensão territorial expressiva, com 1.246.833 $\mathrm{km}^{2}$, o tempo atmosférico sobre o Estado, além dos efeitos locais, é também influenciado por sistemas de mesoescala, como aglomerados convectivos e linhas de instabilidade, e sistemas meteorológicos de grande escala transientes como as zonas frontais, e quase-estacionários, sobretudo, a Zona de Convergência Intertropical-ZCIT e a Zona de Convergência do Atlântico SulZCAS (COHEN, 1989; COHEN; DIAS; NOBRE, 1989; FIGUEROA; NOBRE, 1990; COELHO; DRUMOND; AMBRIZZI, 1999; QUADRO et al., 2012). Assim sendo, a atuação dos diferentes sistemas meteorológicos resulta em uma distribuição pluviométrica elevada (Figura 3), porém não homogênea. Desta forma, integrar as redes de pluviômetros existentes e distribuídas na Amazônia Oriental, até então, representa um avanço para a climatologia da precipitação no Estado, obtendo um detalhamento até então não alcançado. Isto é claramente observado na Figura 3 quando são comparados os quatro bancos de dados anteriormente descritos: GPCP (Global Precipitation Climatology Project), CMAP 
(Climate Prediction Center Merged Analysis of Precipitation), CPC (Climate Prediction Center) e RPCH (Rede Estadual de Previsão Climática e Hidrometeorológica).

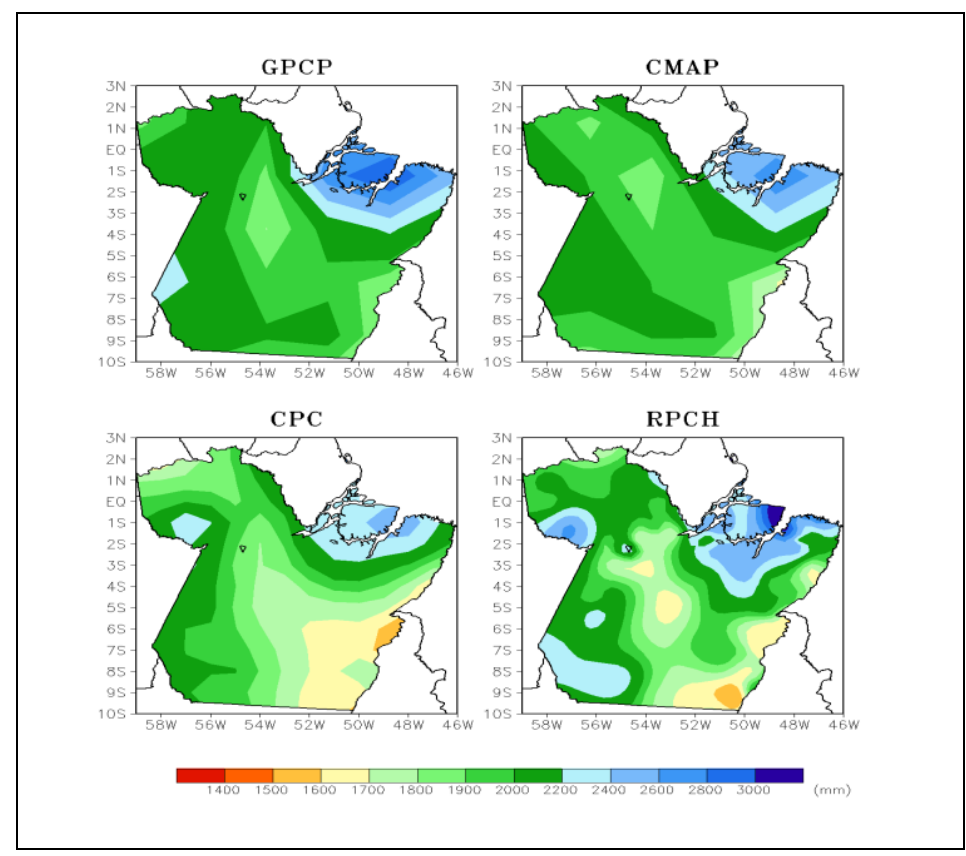

Figura 3. Precipitação média anual. Dados: Global Precipitation Climatology Project (GPCP), Climate Prediction Center Merged Analysis of Precipitation (CMAP), Climate Prediction Center (CPC) e Rede Estadual de Previsão Climática e Hidrometeorológica $(\mathrm{RPCH})$.

Uma análise qualitativa mais geral permite observar a boa consistência entre as diferentes fontes de dados, GPCP, CMAP, CPC-NCEP e RPCH, evidentemente resguardando as limitações inerentes a cada uma delas. A baixa resolução espacial do GPCP e CMAP, por exemplo, produz mapas de pluviometria com regiões geométricas e formas pontiagudas que não são compatíveis com as ocorrências naturais. O CPC minimiza este problema, mas ainda denota certa carência especialmente na região central do Estado, a qual não é tão bem representada. Destaca-se, neste contexto, a precipitação obtida pela RPCH, a qual consegue claramente capturar vários aspectos regionais intrínsecos da distribuição pluviométrica sobre o Pará não percebidos por outras bases. Notase, ainda, que os maiores índices de precipitação durante o ano concentram-se no Nordeste do Estado, com valores superiores a $2.000 \mathrm{~mm}$. Entretanto, regiões do Noroeste e Sudoeste também apontam para tal característica chuvosa. As razões para os elevados índices nas regiões aqui destacadas serão melhores discutidas adiante. Por outro lado, os volumes relativamente mais baixos ficam reservados ao Sudeste paraense, variando de 1.400 a $1.800 \mathrm{~mm}$.

Normalmente, a precipitação exibe certa variabilidade natural de ano para ano em torno destes valores médios aqui apresentados e, consequentemente, uma tolerância com relação aos volumes de chuva acumulados para classificar a sua ocorrência em um intervalo de classe dito "NORMAL". Esta tolerância está diretamente relacionada com a técnica de percentis descrita anteriormente, a qual define os respectivos intervalos. 
A Figura 4 mostra os valores máximos e mínimos de chuva que se espera ocorrer durante um ano sem fenômenos climáticos intensos anômalos atuando sobre a região. Isto significa dizer que, por exemplo, no extremo Sudeste paraense, se em um determinado ano chover apenas $1.150 \mathrm{~mm}$, e no ano seguinte chover $1.650 \mathrm{~mm}$, portanto uma diferença interanual de $500 \mathrm{~mm}$, em ambos os casos, as chuvas são caracterizadas como dentro do NORMAL e, por conseguinte, a diferença observada é resultado apenas de variabilidade climática natural. Todavia, na hipótese das chuvas ficarem acima ou abaixo dos valores apresentados na Figura 4, caracteriza-se, então, um ano anômalo, provocado por eventos climáticos decorrentes de distúrbios oceânicos e/ou atmosféricos.

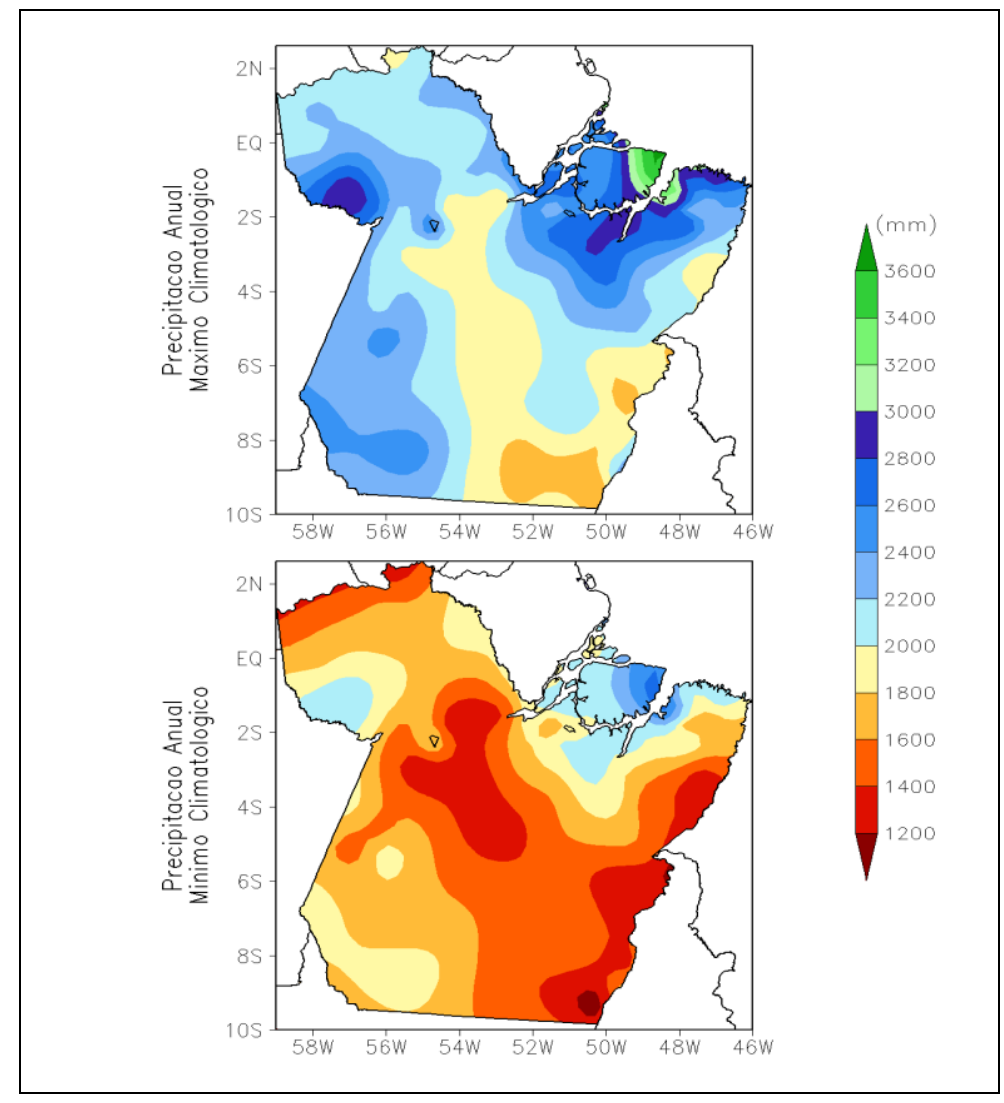

Figura 4. Máximo (percentil 65\%) e mínimo (percentil 35\%) climatológicos da precipitação média anual.

\section{Comportamento sazonal}

Em alguns casos, porém, um fenômeno climático ou a combinação de fenômenos climáticos em diferentes escalas pode estar presente apenas durante alguns meses do ano, provocando variações, exclusivamente, em determinados momentos, e que podem ser atenuadas no decorrer do período, de maneira que o acumulado no ano não evidencia, necessariamente, o comportamento anômalo durante um determinado mês(es) ou estação(ões). Assim, convém analisar também a climatologia e o comportamento sazonal das chuvas (Figura 5). 


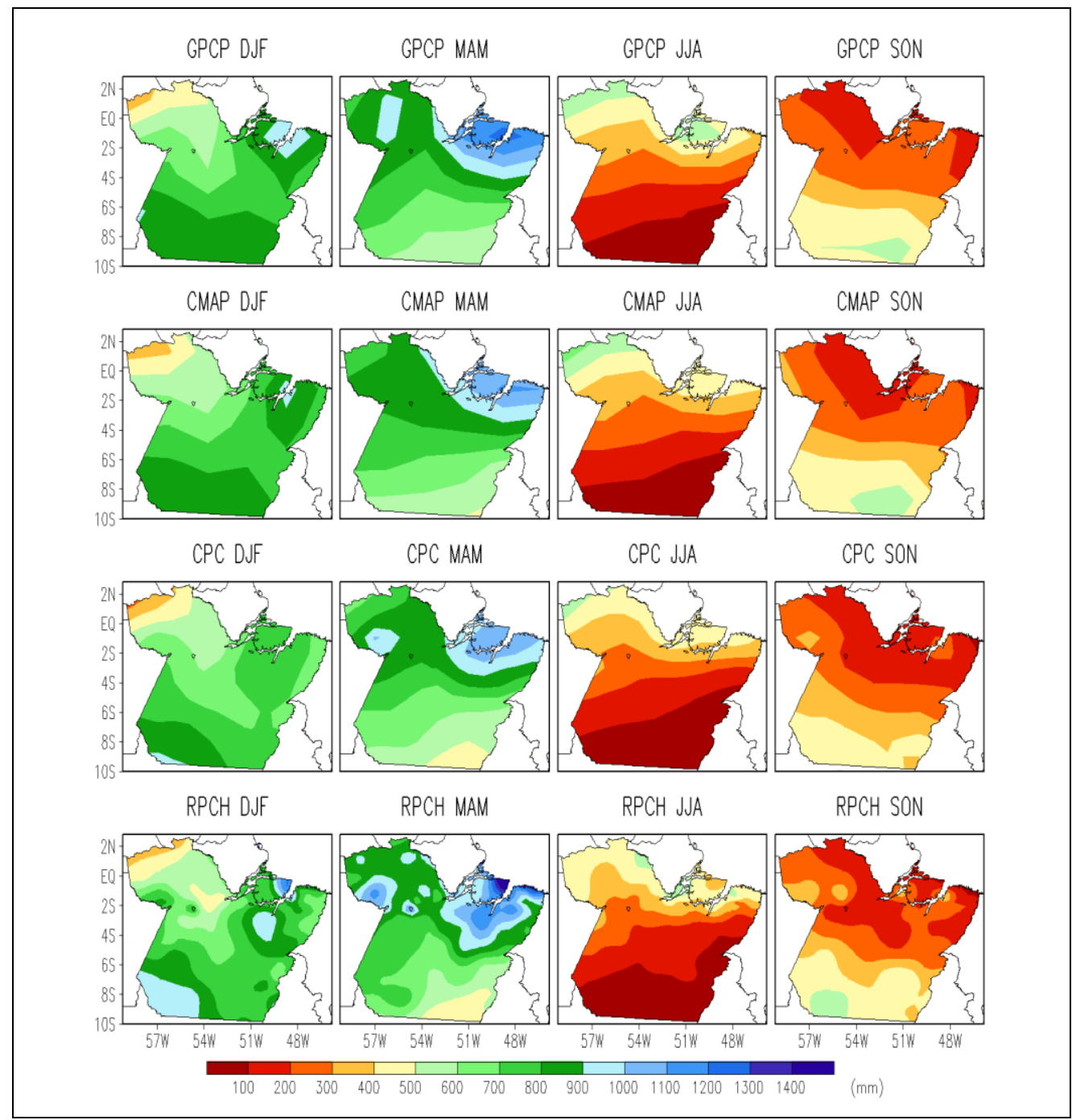

Figura 5. Precipitação média sazonal. Dados: GPCP, CMAP, CPC e RPCH.

Tal qual denota a climatologia para a precipitação anual sobre o Pará, a precipitação sazonal (Figura 5) mantém um padrão semelhante para os quatro conjuntos de dados aqui apresentados, porém salientando mais uma vez que o produto RPCH apresenta isolinhas suavizadas e um maior detalhamento em relação aos demais. Evidencia-se a partir da Figura 5 que o verão e outono austral, seguramente, abrigam os meses mais chuvosos no Pará, coincidindo com o ápice da atividade convectiva na Amazônia Oriental (FISCH; MARENGO; NOBRE, 1998; SOUZA; AMBRIZZI, 2003; SOUZA; KAYANO; AMBRIZZI, 2004). Durante os meses de verão (DJF), o Sul do Estado sofre a influência das incursões de sistemas frontais ou mesmo de ZCAS, provocando elevados níveis pluviométricos, especialmente, no Sudoeste em razão da orientação Noroeste/Sudeste da ZCAS e, também, pela convecção organizada pela Alta da Bolívia ( $A B)$, que surge em decorrência do forte aquecimento no altiplano boliviano (FIGUEROA; NOBRE, 1990; COELHO; DRUMOND; AMBRIZZI, 1999; SOUSA, 2004). Outro importante sistema gerador de precipitação na região, a ZCIT, muito embora do ponto de vista climatológico ainda não se encontre na 
posição mais ao Sul, mesmo nesta época já favorece o aumento da ocorrência de aglomerados convectivos no Nordeste, concorrendo para a elevação dos níveis pluviométricos. Ainda no verão, a $A B$ favorece a formação de um cavado corrente abaixo em altos níveis da troposfera sobre o NEB (Figura 6), que pode fechar-se, constituindo um vórtice ciclônico (VCAN) com circulação direta, ou seja, ar frio e subsidente no centro, e ar quente e ascendente nas bordas. Este sistema, de acordo com o seu posicionamento, pode provocar chuvas no Nordeste do Pará quando desloca-se de Leste para Oeste, visto que a borda do vórtice adquire grande vorticidade, causando instabilidade em baixos níveis (GAN; KOUSKY, 1986).

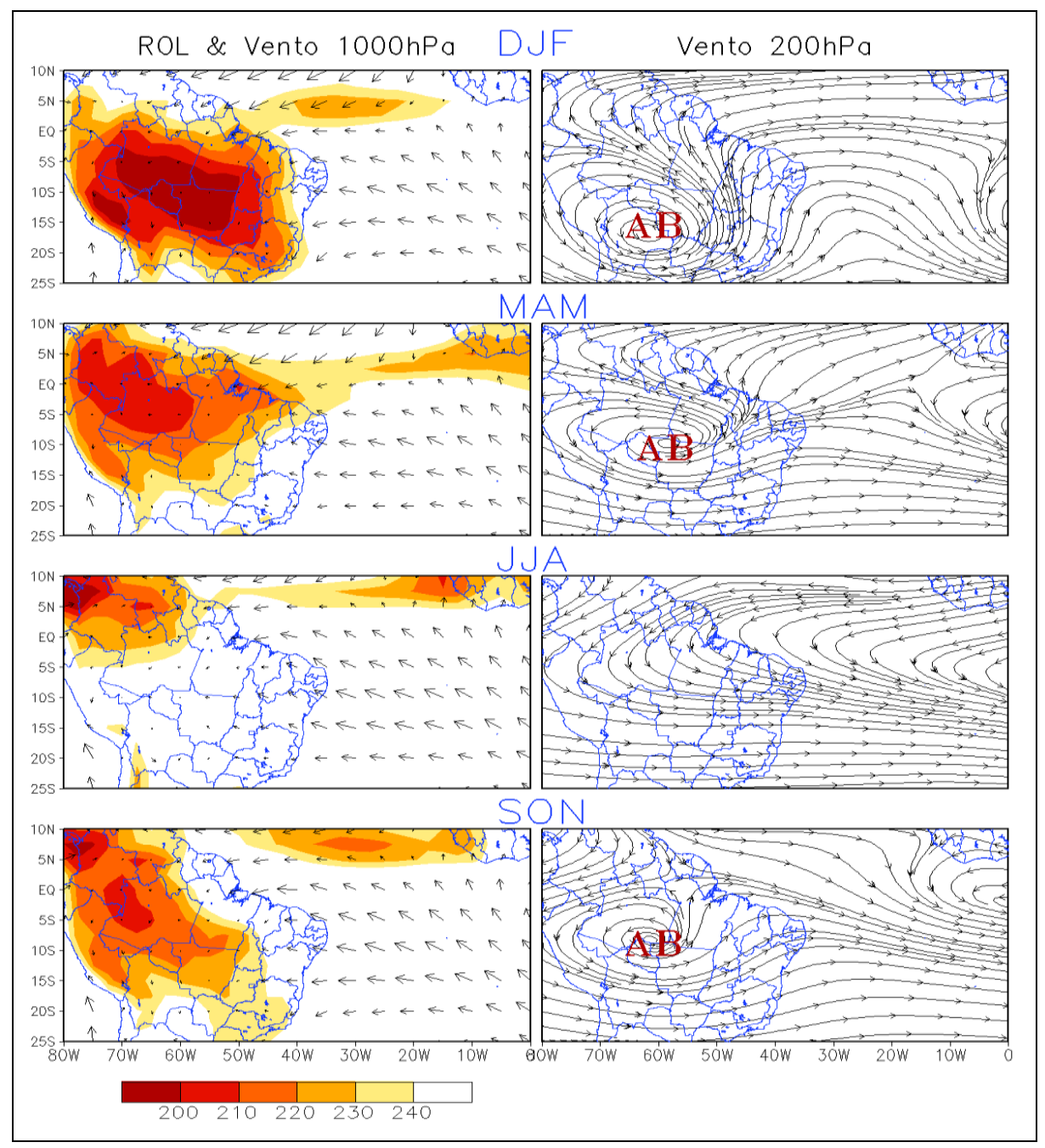

Figura 6. Climatologia sazonal da circulação em $1000 \mathrm{hPa}$ (vetores) e $200 \mathrm{hPa}$ (linhas de corrente), e da radiação em ondas longas-ROL (sombreamento) em $\mathrm{W} \cdot \mathrm{s}^{-2}$. As iniciais $A B$ representam o centro da Alta da Bolívia. Dados: National Center for Environmental Prediction (NCEP).

O máximo de precipitação ocorre no Nordeste paraense, mais precisamente durante o trimestre MAM (outono no hemisfério Sul), quando a ZCIT penetra mais intensamente no continente, situando-se na sua posição mais ao Sul 
durante o ano, fortalecida pelas circulações monçônicas de Nordeste, ou alísios (ZHOU; LAU, 1998). Esta constitui uma forçante dinâmica que favorece em grande parte a formação de aglomerados convectivos que originam precipitação abundante sobre a região. Além disso, a AB desloca-se para o Norte (Figura 6), aproximando-se do Estado e, organizando e intensificando a convecção em todo o Pará.

No outono austral, na região acima do paralelo de $05^{\circ} \mathrm{S}$, encontram-se os maiores índices pluviométricos. Entretanto, percebe-se que o setor Oeste desta região apresenta certa irregularidade na distribuição das chuvas, com a presença de pequenos núcleos. Esta condição é favorecida principalmente por dois fatores: a convecção tropical e a atuação de linhas de instabilidade. A convecção tropical é responsável pela formação de aglomerados convectivos de mesoescala que resultam em grande variabilidade espacial das chuvas, ocasionando o surgimento de vários núcleos de elevada precipitação. $E$ as linhas de instabilidade que, frequentemente, se formam na região costeira, preferencialmente, no período da tarde, devido à circulação de brisa, deslocando-se, basicamente, de Leste para Oeste. Todavia, durante a noite, com a ausência de radiação solar, a perturbação perde força, tornando a se intensificar novamente no dia seguinte (MOLION, 1987; COHEN; DIAS; NOBRE, 1989; FISCH; MARENGO; NOBRE,1998). Assim, há uma região entre o Nordeste e o Noroeste paraense com menor pluviosidade. Esta característica regional é claramente evidenciada na precipitação RPCH (Figuras 3, 4 e 5).

O inverno austral é caracterizado por forte redução nas chuvas, sobretudo na porção Centro-Sul do Pará. Neste período, passa a atuar o ramo descendente da circulação de Hadley, inibindo a formação de nebulosidade no setor Sul do Estado (ROCHA; NOBRE; BARROS, 1989; FISCH; MARENGO; NOBRE, 1998), ocasionando índices pluviométricos sazonais inferiores a $100 \mathrm{~mm}$ em média, proporcionando, portanto, um período mais seco. Esta condição dinâmica, não raro, conduz os municípios localizados nas proximidades de Conceição do Araguaia, Santana do Araguaia e Redenção, no Sudeste paraense, a um mês ou mais absolutamente secos, ou seja, sem qualquer registro de precipitação.

O deslocamento aparente do Sol rumo ao hemisfério Norte conduz a ZCIT a sua marcha sazonal em direção àquele hemisfério, privando o hemisfério Sul da sua atuação decisiva durante o trimestre JJA para produção de chuvas abundantes sobre o Pará. A porção mais ao Norte do Estado inicia, então, neste momento um período de transição da estação chuvosa (inverno Amazônico) para a menos chuvosa (verão Amazônico). Percebe-se ainda, uma mudança drástica no padrão da circulação de ar superior, em razão do resfriamento da superfície sobre o Brasil Central e, consequente, descaracterização da AB.

A primavera no Pará é caracterizada pelo deslocamento do máximo de precipitação para o Sul do Estado, o qual passa a sofrer incursões mais frequentes de sistemas frontais e eventuais episódios de ZCAS. Neste período, a ZCIT encontra-se entre $05^{\circ} \mathrm{N}$ e $10^{\circ} \mathrm{N}$, tornando a região Centro-Norte sujeita, basicamente, à ação única de forçantes termodinâmicas, que provocam apenas pancadas de chuva de curta duração e não proporcionam grandes volumes de chuva. Durante o trimestre $S O N$, ocorre o surgimento da $A B$, mas ainda não tão intensa quanto no verão, porém suficientemente forte para organizar a convecção no Sudoeste/Sul paraense, onde aparece um núcleo de precipitação máxima.

A seguir, é apresentada a variabilidade sazonal da precipitação sobre o Pará (Figura 7) de acordo com os limites considerados normais para cada período. A 
Figura 7 permite observar que a região Sul do Estado é a que apresenta a maior variação sazonal e o Noroeste a que experimenta menor variabilidade sazonal.

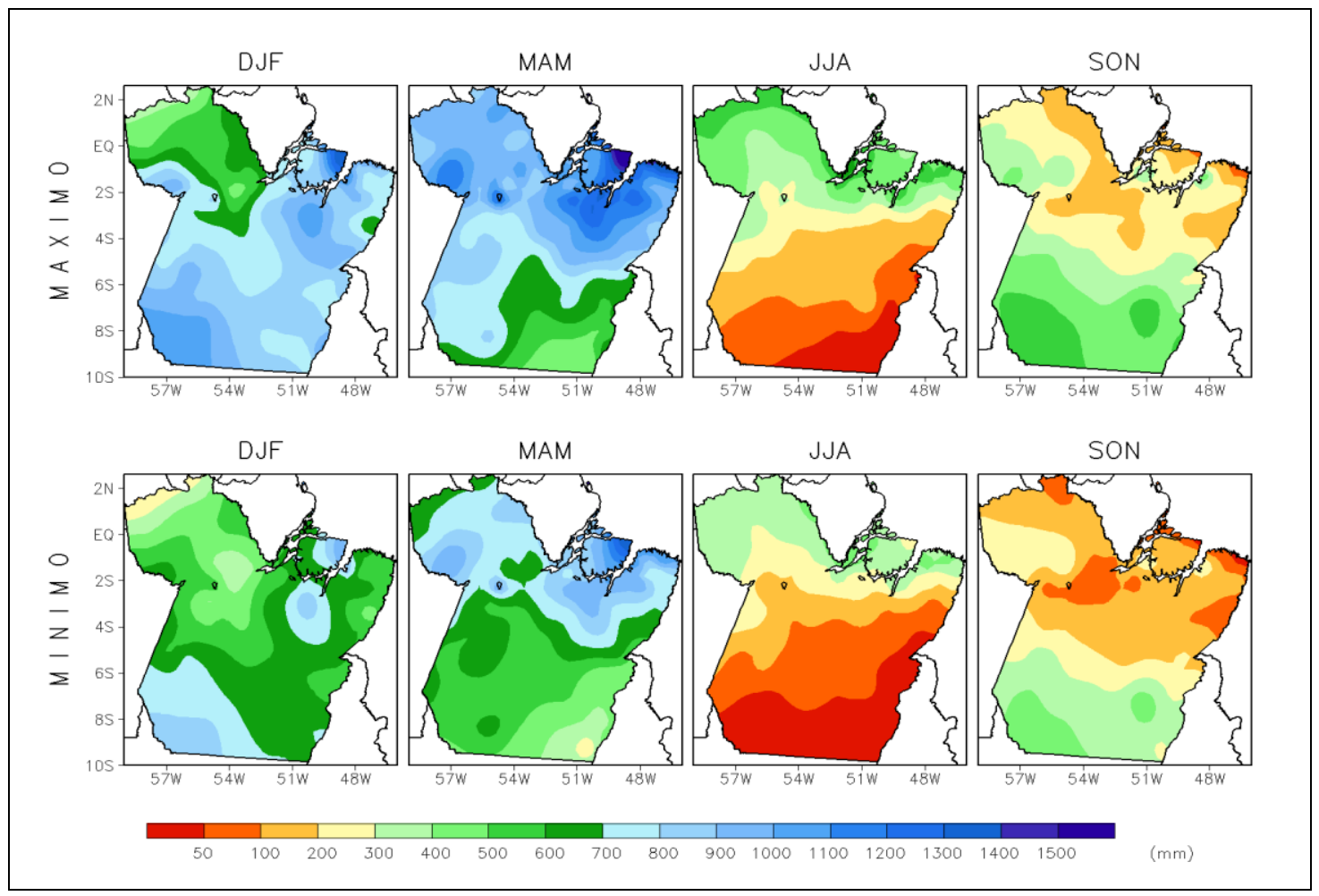

Figura 7. Máximos e mínimos climatológicos da precipitação sazonal. Dados: RPCH.

\section{Comportamento mensal}

A análise da precipitação compartimentada mês a mês é apresentada a seguir (Figura 8). Ao se comparar a climatologia mensal da precipitação para cada diferente base, torna-se mais aparente o ganho obtido através da integração de diversas redes. O mês de janeiro, por exemplo, apresenta máximos no Nordeste paraense que não são observados pelo $C P C$, cuja resolução espacial, $1.0^{\circ}$ latitude $\times 1.0^{\circ}$ longitude, supera O GPCP e CMAP. Ainda no mesmo mês, $O$ CMAP homogeneíza a precipitação no Centro-Sul do Estado, não mostrando qualquer variabilidade espacial; enquanto que o GPCP, embora consiga perceber o padrão das chuvas na região, não é capaz de mostrar detalhadamente a variabilidade regional.

Essas características são mantidas, principalmente, na estação chuvosa, com grandes áreas homogêneas de precipitação, especialmente nos dados do GPCP e CMAP, e em menor grau no CPC. Diferentemente, a base RPCH destaca os pequenos núcleos característicos de padrões climáticos tropicais, da regionalização e dos efeitos da fisiografia local, típicos da intensa convecção resultando em uma espacialização irregular das chuvas. No período menos chuvoso ou seco, as diferenças tornam-se menos acentuadas, sobretudo no trimestre que inicia em julho e vai até setembro, em razão da redução significativa nos volumes de chuvas. 


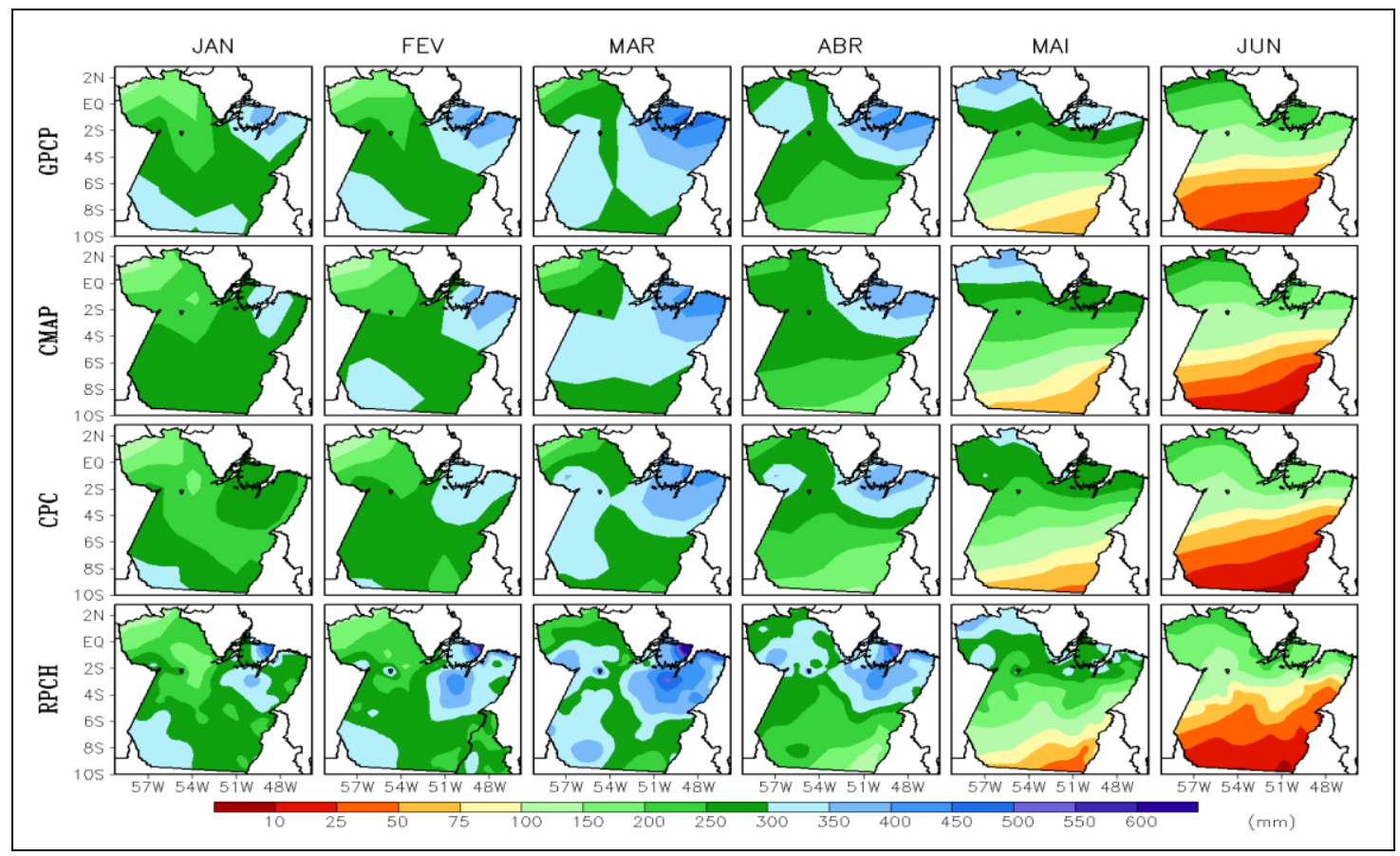

Figura 8a. Média mensal da precipitação. Dados: GPCP, CMAP, CPC e RPCH.

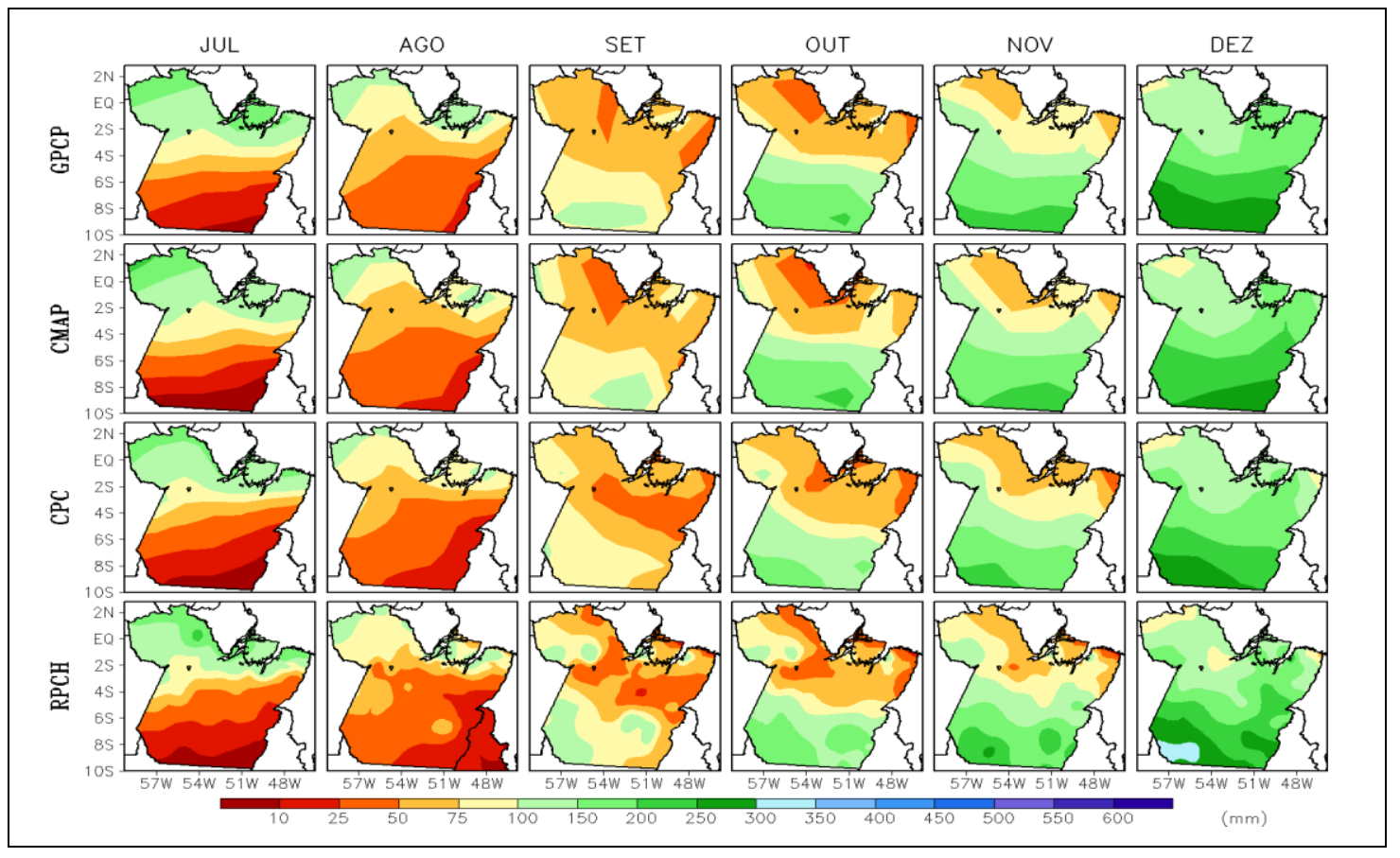

Figura 8b. Média mensal da precipitação. Dados: GPCP, CMAP, CPC e RPCH. 
A Figura 9 apresenta os máximos e mínimos climatológicos distribuídos mensalmente, de acordo com a base do RPCH e a metodologia de percentil adotada.

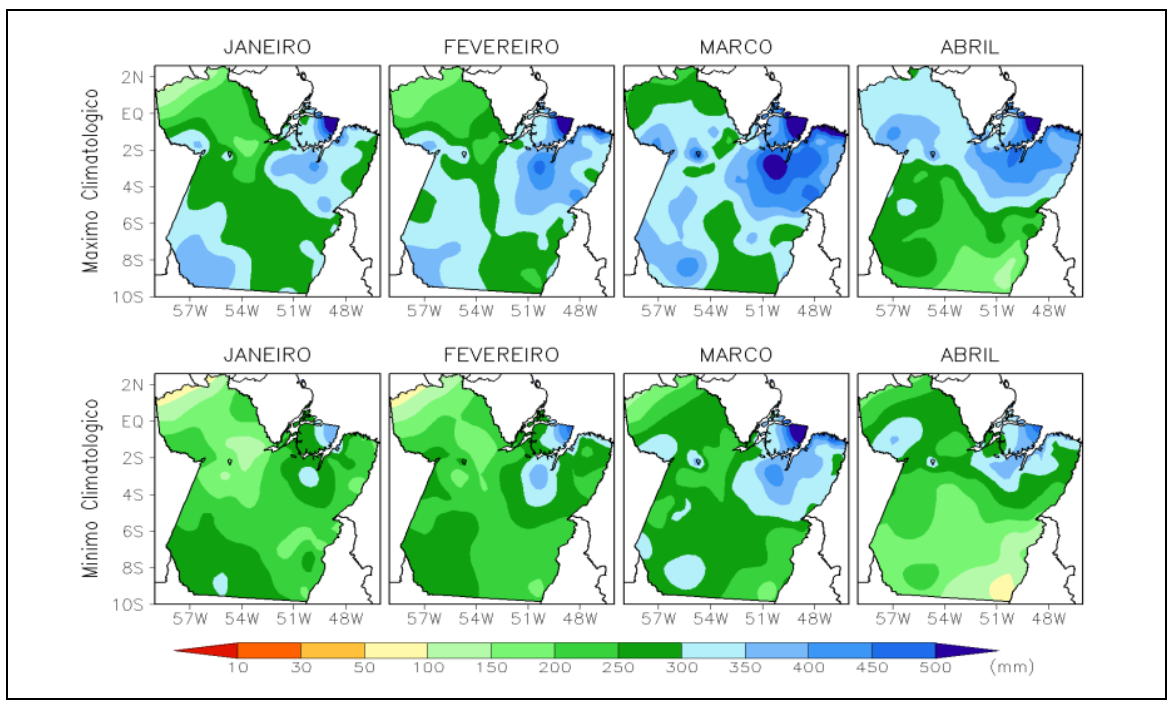

Figura 9a. Máximos e mínimos climatológicos da precipitação mensal. Dados: RPCH.

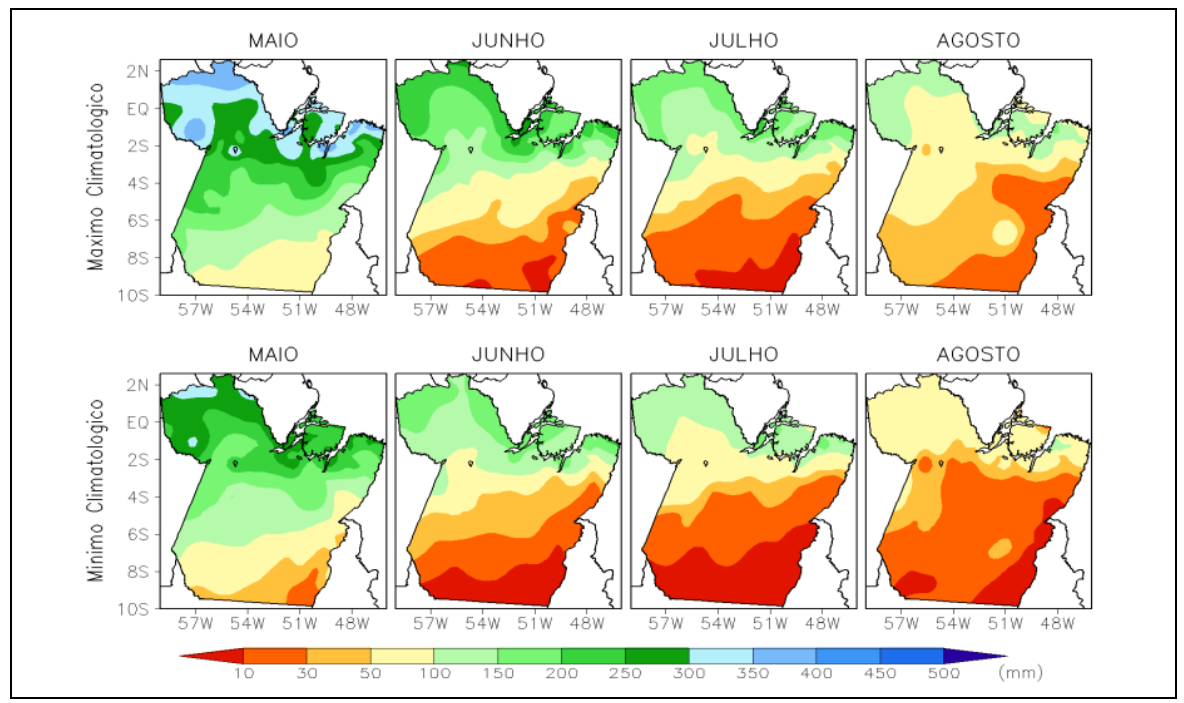

Figura 9b. Máximos e mínimos climatológicos da precipitação mensal. Dados: RPCH. 


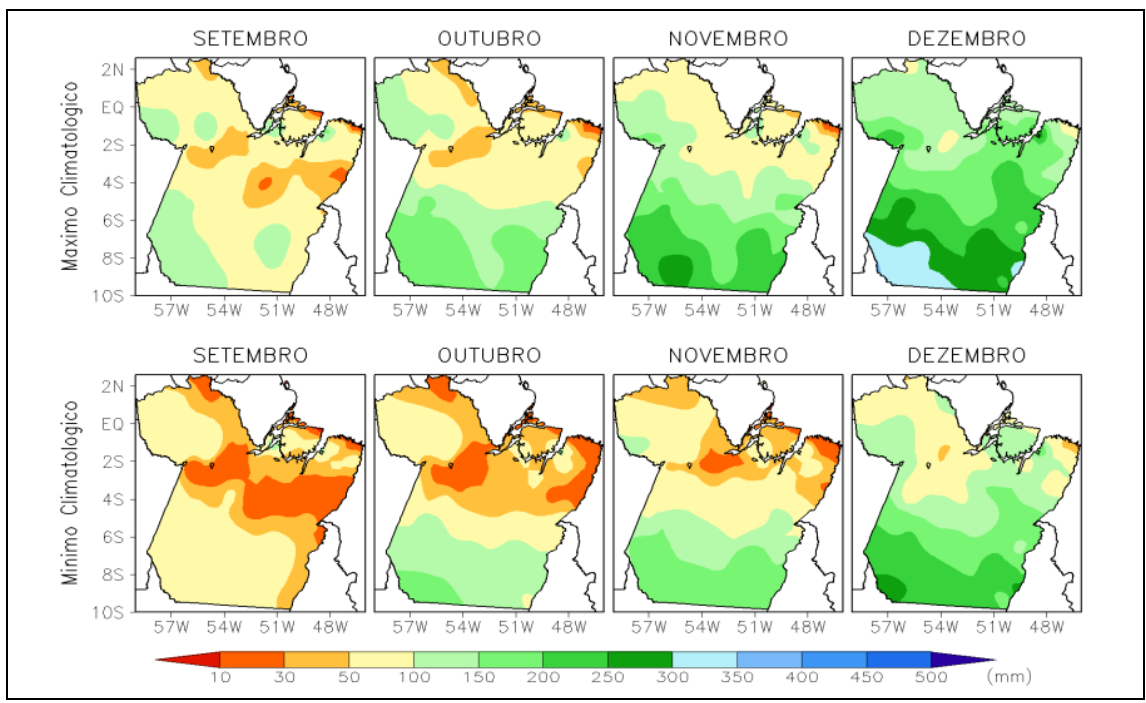

Figura 9c. Máximos e mínimos climatológicos da precipitação mensal. Dados: RPCH.

\section{CONCLUSÕES}

O presente trabalho realizou um estudo em climatologia regional com uma abordagem observacional focada no estado do Pará e apresentou dados pluviométricos para a região aperfeiçoando e melhor descrevendo a distribuição espacial da chuva em diferentes escalas de tempo.

Após a análise de dados de quase duzentas estações meteorológicas, chegou-se a 150 estações, cujos dados foram devidamente consistidos, gerando uma base nova, com melhor cobertura e mais densa, capaz de gerar informações com maior grau de detalhamento. O primeiro produto obtido a partir deste novo banco de dados foi a climatologia regionalizada da precipitação no estado do Pará. Notadamente, sistemas meteorológicos de pequena e mesoescala, típicos da região tropical onde a convecção exerce grande influência no regime e distribuição espacial das chuvas, apresentam seus efeitos claramente perceptíveis na climatologia $\mathrm{RPCH}$, mesmo quando se trata de um mapa climatológico anual, passando pela escala sazonal até chegar à mensal. A partir desta nova base, torna-se eminente a não-homogeneidade espacial das chuvas no Pará influenciada inclusive pela topografia, hidrografia e outros aspectos mais da fisiografia particular do Estado.

O Nordeste paraense mostrou-se, como esperado, o setor mais chuvoso do Estado ao longo do ano, porém, diferentemente do que se conhecia até então, evidencia-se um núcleo de precipitação significativa no Noroeste, podendo surgir outros centros de precipitação no outono, embora menos intensos. Ao mesmo tempo, a ilha do Marajó apresentou certa variabilidade espacial na estação chuvosa, com índices mais expressivos na porção Leste, marcadamente influenciada por circulações de brisa e, principalmente, pela ZCIT, com volume de chuvas reduzindo-se em direção ao Oeste.

Destaca-se, também, o setor Sudoeste, onde as chuvas no verão austral, de acordo com a climatologia, são bastante superiores às bases com mais baixa resolução, como GPCP, CMAP e CPC. Nesta época, o posicionamento da AB, já estabelecida, intensifica a convecção na região, constatação ratificada pelo dado de chuva acumulada observado em melhor resolução da base RPCH. 
Em síntese, esta nova climatologia permitiu destacar as peculiaridades da distribuição espacial e temporal da precipitação de uma área extensa como é o estado do Pará, destacando os limites naturais da variabilidade climática na ausência de forçantes anômalas do clima. Este dado tem aplicação direta em diversos setores da economia do Estado, tais como comércio, indústria, turismo, agricultura e pecuária, produção mineral e energia elétrica, e diversos outros setores, especialmente aqueles ligados aos recursos hídricos, e para a sociedade civil de uma forma geral.

\section{AGRADECIMENTOS}

Este trabalho é parte integrante da dissertação de mestrado do Programa de Pós-Graduação em Ciências Ambientais-PPGCA/UFPA e contou com financiamento da FINEP e a colaboração do Instituto Nacional de Meteorologia, Agência Nacional de Águas, Secretaria Estadual de Meio Ambiente do Pará, Companhia de Pesquisa e Recursos Minerais, instituições de reconhecida relevância no cenário nacional e regional, às quais os autores manifestam seus sinceros agradecimentos.

\section{REFERÊNCIAS}

ADLER, R.F. et al. The Version 2 Global Precipitation Climatology Project (GPCP) Monthly Precipitation Analysis (1979-Present). Journal of Hydrometeorology, v.4, p.11471167. 2003.

CLIMATE PREDICTION CENTER MERGED ANALYSIS OF PRECIPITATION - CMAP, 2008. Disponível em: ftp://ftp.cdc.noaa.gov/Datasets/cmap/enh/. Acesso em março de 2008.

COELHO, C. A. S.; DRUMOND, A. R. M.; AMBRIZZI, T. Estudo climatológico sazonal da precipitação sobre o Brasil em episódio extremo da Oscilação Sul. Revista Brasileira de Meteorologia, v.14, n.1, p.49-65. 1999.

COHEN, J. C. P. Um estudo observacional de linhas de instabilidades na Amazônia. 1989, 174f. Dissertação (Mestrado em Meteorologia) - Instituto Nacional de Pesquisas Espaciais, INPE, São Paulo. 1989.

COHEN, J. C. P; DIAS, M. A. F. S.; NOBRE, C. A. Aspectos climatológicos das linhas de instabilidade na Amazônia. Climanálise - Boletim de Monitoramento e Análise Climática, v.4, n.11, p.34-40. 1989.

CLIMATE PREDICTION CENTER - CPC, 2008. Disponível em: ftp://ftp.cpc.ncep.noaa.gov/precip/wd52ws/SA/. Acesso em março de 2008.

FIGUEROA, S. N.; NOBRE, C. A. Precipitation distribution over central and western tropical South America. Climanálise - Boletim de Monitoramento e Análise Climática, v.5, p.36-45. 1990.

FISCH, G.; MARENGO, J. M.; NOBRE, C. A. Uma revisão geral sobre o clima da Amazônia. Acta Amazônica, v.28, n.2, p.101-126. 1998.

GAN, M. A.; KOUSKY, V. E. Vórtices ciclônicos da alta troposfera no oceano Atlântico Sul. Revista Brasileira de Meteorologia, v.1, p.19-28. 1986.

HIGGINS, R. W. et al. Improved United States precipitation quality control system and analysis. NCEP/Climate Prediction Center Atlas 7, 40p. 2000.

HUFFMAN, G. J. et al. The GPCP combined precipitation dataset. Bulletin of the American Meteorological Society, v.78, n.1, p.5-20. 1997.

Instituto Brasileiro de Geografia e Estatística - IBGE. Contagem da População. Ministério do Planejamento, Orçamento e Gestão. Rio de Janeiro-RJ. 2007. Disponível em http://www.ibge.gov.br/home/estatistica/populacao/contagem2007/contagem.pdf

KALNAY, E. et al. The NCEP/NCAR 40-year reanalysis project. Bulletin of the American Meteorological Society, v.77, n.3, p437-471. 1996.

KAYANO, M. T.; RAO, V. B.; MOURA, A. D. Tropical circulations and the associated rainfall anomalies during two contrasting years. Journal of Climatology, v.8, p.477488. 1988. 
KILADIS, G. N.; DIAZ, H. F. Global climatic anomalies associated with extremes in the Southern oscillation. Journal of Climate, v.2, n.9, p.1069-1090. 1989.

KODAMA, Y. Large-scale common features of subtropical precipitation zones (the Baiu frontal zone, the SPCZ, and the SACZ). Journal of the Meteorological Society of Japan, v.70, n.4, p.813-836. 1992.

KOUSKY, V. E.; KAYANO, M. T.; CAVALCANTI, I. F. A. A review of the Southern oscillation: oceanic-atmospheric circulation changes and related rainfall anomalies. Tellus, v.36A, p.490-504, 1984.

LIEBMANN, B.; SMITH, C. A. Description of a complete (interpolated) outgoing longwave radiation dataset. Bulletin of the American Meteorological Society, v.77, p.1275-1277. 1996.

LIEBMANN, B. et al. Submonthly convective variability over South America and the South Atlantic convergence zone. Journal of Climate, v.12, p.1877-1891. 1999.

MARENGO, J. A. Interannual variability of deep convection in the tropical South American sector as deduced from ISCCP C2 data. International Journal of Climatology, v.15, n.9, p.995-1010. 1995.

MARENGO, J. A. et al. Onset and end of the rainy season in the Brazilian Amazon Basin. Journal of Climate, v.14, p.833-852. 2001.

MOLION, L. C. B. Climatologia dinâmica da região Amazônica: mecanismos de precipitação. Revista Brasileira de Meteorologia, v.2, p.107-117. 1987.

MOLION, L. C. B. Amazonian rainfall and It's variability. Hydrology and water management in the humid tropics. Cambridge: Cambridge University Press, p.99111. 1993.

NOBRE, P.; SHUKLA, J. Variations of SST, wind stress and rainfall over the tropical Atlantic and South America. Journal of Climate, v.9, p.2464-2479. 1996.

NOGUÉS-PAEGLE, J.; MO, K. C. Alternating wet and dry conditions over South America during summer. Monthly Weather Review, v.125, p.279-291. 1997.

PAIVA, E. M. C. D.; CLARK, R. T. Time trends in rainfall records in Amazonia. Bulletin of the American Meteorology Society, v.76, n.11, p.2203-209. 1995.

PARTHASARATHY, B.; MOOLEY, D. A. Some features of a long homogeneous series of Indian summer monsoon rainfall. Monthly Weather Review, v.106, n.6, p.771781.1978

QUADRO, M. F. L. Estudo de episódios de Zona de Convergência do Atlântico Sul (ZCAS) sobre a América do Sul. 1994, 123f. Dissertação (Mestrado em Meteorologia) Instituto Nacional de Pesquisas Espaciais, INPE, São Paulo. 1994.

QUADRO, M. F. L. et al. Análise Climatológica da Precipitação e do Transporte de Umidade na Região da ZCAS Através da Nova Geração de Reanálises. Revista Brasileira de Meteorologia, v. 27, p. 152-162, 2012.

RAMOS DA SILVA, R.; WERTH, D.; AVISSAR, R. Regional Impacts of Future LandCover Changes on the Amazon Basin Wet-Season Climate. Journal of Climate, v.21, p.1153-1170. 2008.

RICKEY, J. E.; NOBRE, C. A.; DESER, C. Amazon River discharge and climate variability: 1903 to 1985 . Science, v.246, p.101-103. 1989.

ROCHA, H. R.; NOBRE, C. A.; BARROS, M. C. Variabilidade natural de longo prazo no ciclo hidrológico da Amazônia. Climanálise - Boletim de Monitoramento e Análise Climática, v.4, n.12, p.36-42. 1989.

ROPELEWSKI, C. F.; HALPERT, M. S. Global and regional scale precipitation patterns associated with the El Niño/Southern Oscillation. Monthly Weather Review, v.115, n.8, p.1606-1626. 1987.

SALATI, E.; MARQUES, J. Climatology of the Amazon region. In: SIOLI, H. (Ed.). The Amazon - Limnology and landscape ecology of a mighty tropical river and its basin. Dr. W. Junk Publishers, 1984. 763p.

SILVA, V. B. S. et al. An improved gridded historical daily precipitation analysis for Brazil. Journal of Hydrometeorology, v.8, p.847-861. 2007.

SOUSA, E. P. P. Relações entre as anomalias de TSM do Atlântico e Pacífico e as precipitações na Amazônia oriental. 2004, 80f. Dissertação (Mestrado em Meteorologia) - Instituto Nacional de Pesquisas Espaciais, INPE, São Paulo. 2004. 
SOUZA, E. B.; NOBRE, P. Uma revisão sobre o padrão de dipolo no Atlântico Tropical. Revista Brasileira de Meteorologia, v.13, n.1, p.31-44. 1998.

SOUZA, E. B. et al. On the influences of the EI Niño, La Niña and Atlantic dipole pattern on the Amazonian rainfall during 1960-1998. Acta Amazônica, v.30, n.2, p.305-318. 2000.

SOUZA, E. B.; AMBRIZZI, T. Pentad precipitation climatology over Brazil and the associated atmospheric mechanisms. Climanálise - Boletim de Monitoramento e Análise Climática, v.1. 2003.

SOUZA; E. B.; KAYANO, M. T.; AMBRIZZI, T. The regional precipitation over the eastern Amazon/northeast Brazil modulated by tropical Pacific and Atlantic SST anomalies on weekly timescale. Revista Brasileira de Meteorologia, v.19, n.2, p.113122. 2004.

SOUZA, E. B.; KAYANO, M. T.; AMBRIZZI, T. Intraseasonal and submonthly variability over the eastern Amazon and Northeast Brazil during the autumn rainy season. Theoretical and Applied Climatology, v.81, p.177-191. 2005.

SOUZA, E. B. et al. Precipitação climatológica sobre a Amazônia oriental durante o período chuvoso: observações e simulações regionais com o RegCM3. Revista Brasileira de Meteorologia, v.24, p.111-124. 2009.

TRENBERTH, K. E. The definition of El Niño. Bulletin of the American Meteorological Society, v.78, n.12, p.2771-2777. 1997.

UVO, C. B. A zona de convergência intertropical (ZCIT) e sua relação com a precipitação da região Norte do Nordeste Brasileiro. 1989, 99f. Dissertação (Mestrado em Meteorologia) - Instituto Nacional de Pesquisas Espaciais, INPE, São Paulo. 1989.

WALISER, D. E.; GAUTIER, C. A satellite-derived climatology of the ITCZ. Journal of Climate, v.6, n.11, p.2162-2174. 1993.

XAVIER, T. M. B. S. Caracterização de Períodos secos ou excessivamente chuvosos no Estado do Ceará através da Técnica dos Quantis: 1964-1998. Revista Brasileira de Meteorologia, v. 14, n.2, p.63-78. 1999.

$X A V I E R, T$. M. B. S. A técnica dos quantis e suas aplicações em meteorologia, climatologia e hidrologia, com ênfase para as regiões brasileiras. Brasília, DF: Thesaurus, 2002. 143p.

XIE, P.; ARKIN, P. A. Global precipitation: a 17-year monthly analysis based on gauge observations, satellite estimates and numerical model outputs. Bulletin of the American Meteorological Society, v.78, p.2539-2558. 1997.

XIE, P.; ARKIN, P. A. Global monthly precipitation estimates from satelliteobserved outgoing longwave radiation. Journal of Climate, v.11, p.137-164. 1998.

ZHOU, J.; LAU, K. -M. Does a Monsoon Climate exist over South America? Journal of Climate, v.11, n.5, p.1020-1040. 1998. 